\title{
Gametes and Embryo Epigenetic Reprogramming Affect Developmental Outcome: Implication for Assisted Reproductive Technologies
}

\author{
SAJI JACOB AND KELLE H. MOLEY \\ Department of Obstetrics \& Gynecology [S.J., K.H.M.], Washington University School of Medicine, St. \\ Louis, MO 63110; and Department of Ob/Gyn [S.J.], Southern Illinois Healthcare Foundation, Alton, IL \\ 62003
}

\begin{abstract}
There is concern about the health of children who are conceived with the use assisted reproductive technologies (ART). In addition to reports of low birth weight and chromosomal anomalies, there is evidence that ART may be associated with increased epigenetic disorders in the infants who are conceived using these procedures. Epigenetic reprogramming is critical during gametogenesis and at preimplantation stage and involves DNA methylation, imprinting, RNA silencing, covalent modifications of histones, and remodeling by other chromatinassociated complexes. Epigenetic regulation is involved in early embryo development, fetal growth, and birth weight. Disturbances in epigenetic reprogramming may lead to developmental problems and early mortality. Recent reports suggest the increased incidence of imprinting disorders such as BeckwithWiedemann syndrome, Angelman syndrome, and retinoblastoma in children who are conceived with the use of ART. These may result from an accumulation of epigenetic alterations during embryo culture and/or by altered embryonic developmental timing. Further research is urgently needed to determine whether a causal relationship between ART and epigenetic disorders exists. Until then, cautious review of both short-term and long-term ART outcomes at a national level is recommended. (Pediatr Res 58: 437-446, 2005)
\end{abstract}

\section{ABSTRACT}

\author{
Abbreviations \\ ART, assisted reproductive technologies \\ AS, Angelman syndrome \\ ATRX, X-linked $\alpha$-thalassemia/mental retardation \\ BWS, Beckwith-Wiedemann syndrome \\ DNMT, DNA methyltransferase \\ FMR1, fragile X mental retardation gene 1 \\ HDAC, histone deacetylase \\ ICF, immunodeficiency, centromeric instability and facial \\ anomalies \\ IVF, in vitro fertilization \\ LBW, low birth weight \\ LOI, loss of imprinting \\ LOS, large offspring syndrome \\ MBD, methyl-binding domain \\ $\mathbf{R B}$, retinoblastoma \\ RTS, Rubinstein-Taybi syndrome \\ RTT, Rett syndrome \\ UPD, uniparental disomy \\ VLBW, very low birth weight
}

Recent reports of birth defects and health problems in children who are conceived with assisted reproductive technologies (ART) has led to the initiation of prospective and retrospective follow-up studies in these children to evaluate the safety of these techniques. These investigations have determined that development is normal and that malformation rates are either similar or only slightly greater than those in the general population $(1,2)$. These studies, however, have also revealed a lower birth weight in the in vitro fertilization (IVF)

Received February 4, 2005; accepted April 18, 2005

Correspondence: Kelle H. Moley, M.D., Washington University School of Medicine, Department of Obstetrics \& Gynecology, Campus Box 8064, St. Louis, MO 63110; e-mail: moleyk@wustl.edu

DOI: 10.1203/01.PDR.0000179401.17161.D3 and ICSI singletons as compared with naturally conceived children (3-5). It has been postulated that embryos in culture may acquire epigenetic defects as a result of the abnormal environmental conditions that may lead to these aberrant phenotypes. Several lines of evidence support this hypothesis. The accumulation of severe epigenetic disturbances above a certain threshold may lead to early mortality. Alternatively, embryos that develop to term may still have epigenetic defects, and these may result in obvious aberrant phenotypes or in subtle changes in gene expression that can be easily overlooked. These epigenetic reprogramming disturbances can occur at gametogenesis or at preimplantation embryo stage and could be influenced by in vitro culture conditions. This review explores epigenetic reprogramming in the gametes and embryo 
and how normal epigenetic modification may be influenced by ART.

\section{INTRODUCTION TO EPIGENETICS}

Epigenetic changes are defined as chemical alterations to the DNA or to the histone proteins associated with it that change the structure without altering the nucleotide sequence. The DNA, complexed together with the histones, make up chromatin. These epigenetic changes modify the structure of the chromatin by making it more condensed or more open. These changes in turn affect gene expression within the DNA by either allowing or preventing accessibility to the DNA of the factors involved with transcription.

Unintended gene silencing caused by epigenetic modifications has been linked to several human diseases. Specifically, DNA methylation and histone deacetylation are the major forms of epigenetic modifications that occur in tumors. DNA methylation is a chemical modification of the DNA molecule itself, which is regulated by an enzyme called DNA methyltransferase (DNMT). Methylation can directly switch off gene expression by preventing the ability of transcription factors to access DNA and binding to promoters. Another chemical modification of DNA is histone deacetylation. In this process, enzymes called histone deacetylases (HDACs) are associated with methyl-binding domain (MBD) proteins and are attracted to DNA. Activation of these HDACs leads to alteration of the histones and chromatin structure, thereby causing the chromatin condensation, inaccessibility of the DNA promoters, and gene silencing (see Fig. 1).
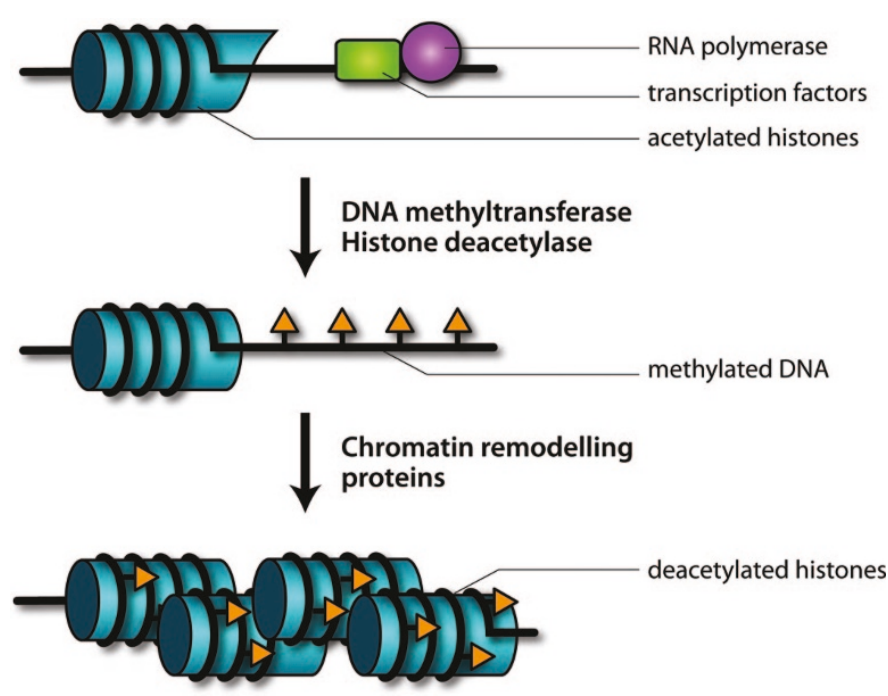

Figure 1. Epigenetic modifications that silence gene expression. (Top) Open chromatin is characterized by nonmethylated DNA and histones with acetylated tails. This permits accessibility of the DNA promoters with assembly of transcription factors and transcription by RNA polymerase. (Middle) Activity of DNMT leads to methylation of DNA. This event may directly block binding by transcription factors and prevent transcription. In addition, this event may attract and recruit MBD proteins that have associated HDACs. (Bottom) DNA methylation and histone deacetylation result in the condensation of chromatin into a compact state that is inaccessible by transcription factors.

\section{EPIGENETIC REPROGRAMMING}

Epigenetics is commonly defined as the study of heritable changes in gene function that occur without a change in the DNA sequence. Epigenetic modifications work in concert with the genetic information of a DNA sequence. These modifications include DNA methylation, imprinting, RNA silencing, covalent modifications of histones, and remodeling by other chromatin-associated complexes. All of these alterations regulate gene expression. These are referred to as epigenetic patterns, and they are normally built into the genome during differentiation through genetically determined programs. Additional epigenetic alterations to the DNA allow cells to alter the expression level of the different genes in response to environmental factors without having to change the DNA code itself.

Inheritance or persistence of these epigenetic modifications is referred to as epigenetic reprogramming. The most critical periods at which epigenetic reprogramming occurs are those during gametogenesis and the preimplantation embryonic stage (6). Reprogramming during gametogenesis is essential for the imprinting mechanism that regulates the differential expression of paternally and maternally derived genes. Primordial germ cells undergo demethylation, both globally (7) and within imprinted loci as they migrate along the genital ridge $(7,8)$. After this demethylation or erasure, which ensures genetic totipotency, $\mathrm{CpG}$ methylation of imprinted genes is reestablished during gametogenesis through de novo methylation, in both eggs (9) and sperm (10). Imprints are established differentially in sperm and oocyte and are maintained in the embryo and further through all somatic cell divisions. Methylation and chromatin remodeling take place with each cell division and provide the germ cell genome with molecular blueprints for oocyte activation and embryonic development. There are significant differences between mature oocytes and sperm in epigenetic organization. The sperm genome is more methylated than the oocyte genome. The chromatin is well compacted with protamines in sperm but with histones in oocytes. The oocyte chromatin structure is more "closed" than that of sperm cells. Finally, imprinted loci are differentially methylated among sperm and oocytes. At fertilization, the oocyte and sperm genomes are transcriptionally silent. After fertilization, chromosomes from the sperm decondense and are remodeled. Protamines are exchanged for maternal histones as rapid demethylation takes place (11). The oocyte genome is demethylated more slowly by a passive mechanism (12). Genes that are imprinted with methylation marks, however, are protected from demethylation (13), so parental imprints are maintained. At the time of implantation, de novo methylation occurs genome-wide in a lineage-specific pattern (14). Epigenetic reprogramming during the preimplantation period is essential for correct development because this phenomenon regulates expression of early embryonic genes, cell cleavage, and cell determination. As the organism ages, the early embryonic genes are silenced and tissue-specific genes are expressed. Imprinted genes maintain their methylation marks from the germ cell stage, and they avoid these general erasure processes of the preimplantation stage. 
Consequence of disturbances in epigenetic programming. Aberrant or incomplete epigenetic reprogramming at the preimplantation embryo stage or earlier may result in developmental delays and embryonic lethality. The epigenetic disturbances that are tolerated may result in phenotype changes that will manifest at a later stage. Epigenetic modifications are normally erased in the germ line, whereas genetic mutations or modifications are not. Partial erasure results in epigenetic inheritance as demonstrated by the epigenetic inheritance of the Avy allele in mice (15). Epigenetic changes that occur shortly after fertilization, before specification of the germ line, will involve both somatic cells and germ-line cells and thus be transmitted to the next generation (16). Currently, only a few examples of epigenetic inheritance in mammals are known. Methylation blueprints in humans have been shown to be inherited to some degree (17). Somatic cell nuclear transplantation experiments with early mouse embryos have resulted in altered patterns of gene expression that have resulted in phenotype changes (reduced body weight) later in development. These epigenetic changes were transmitted to the majority of offspring of the manipulated parent mice (18). Another example is the unexpectedly increased perinatal mortality and low birth weight observed in the children of women who were malnourished in the first and second trimesters of their own fetal development during the Dutch famine of 1944-1945 (19). Despite that these women were not underweight at birth, their offspring manifested abnormalities. It was concluded that in response to the malnutrition, epigenetic deregulation in the fetuses occurred at the level of germ cells. This phenomenon may represent a lack of epigenetic erasure that may not give rise to phenotype changes in the affected offspring but could be transmitted to the next generation. Given these examples, it is possible that incomplete epigenetic modifications in the embryos conceived by IVF and ICSI may be responsible for the reported birth weight difference in these children (3-5). If this is true, then it is also possible that both somatic and germ cells will be affected and that these changes would be reflected not only in the ART-conceived infants but also in their progeny.

Epigenetics and development. Epigenetics plays a major role in many aspects of normal mammalian development. The process of embryogenesis is epigenetically controlled. Knockout studies in mice null for DNMTs and histone modifiers result in embryonic lethality (20-22). In addition, both maternal and paternal chromosomes are required for normal development (23). Fetuses with maternal disomy have poor extraembryonic membrane development with less impaired embryonic development, whereas fetuses with paternal disomy have poor embryonic development with considerably less effect on development of the extraembryonic membranes. Finally, as a result of somatic cell nuclear transfer studies, it now is clear that differentiated, tissue-specific genetic information is reprogrammable under the right conditions and by definition is epigenetic. The genome of the new pluripotent blastocyst is identical to the genome of the differentiated somatic cell from which the DNA is obtained, but the information content is modified as demonstrated by the altered methylation pattern reported in cloned bovine embryos (24).
Some imprinted genes are responsible for regulating fetal size or birth weight (25). Disruption of the imprinted mouse gene Igf2 results in growth retarded offspring (26), whereas overexpression of the transgene results in fetal overgrowth (27). Similarly, loss of imprinting (LOI) of Igf2 also results in a mouse model of Beckwith-Wiedemann syndrome (BWS), consistent with macrosomia (28). Uniparental disomy (UPD) for an area of chromosome 11 reflects overgrowth when there is paternal duplication and growth deficiency when there is maternal duplication (24). This finding supports the Haig hypothesis, which proposes that genomic imprinting evolved to match the paternal evolutionary bias to increase fetal growth with the maternal evolutionary bias to restrict fetal size (29).

Genetic disorders caused by (de)methylation and/or (de)acetylation. DNA methylation is caused by chemical modification of the DNA and is regulated by enzymes called DNMTs. Of the five DNMTs described, DNMT1 prefers hemimethylated DNA as a substrate and hence is referred to as "maintenance methyltransferase." Mouse oocytes and preimplantation embryos lack DNMT1 but express a variant of this protein called DNMT1o, which provides maintenance methyltransferase activity specifically at imprinted loci during the fourth embryonic S phase (30). DNMT3A and DNMT3B are referred to as "de novo methyltransferases" because they prefer nonmethylated DNA. The fifth protein, DNMT2, has strong sequence and structural affinities with DNMTs but has not shown transmethylase activity in biochemical or genetic tests (31). DNMT1 and DNMT3b gene dysfunction results in midgestation embryo demise. DNMT3a knockout mice live but fail to thrive and die soon after birth (32). DNA methylation attracts methyl-CpG binding proteins, such as MECP2, that have associated HDACs and bind to the methylated regions. The histone deacetylation results in chromatin condensation, thus causing the chromatin to be inaccessible to transcription factors in promoter regions (33). DNA methylation is also transcriptionally regulated. Human CpG-binding protein is a transcriptional activator that binds specifically to unmethylated $\mathrm{CpG}$ dinucleotides, modulating the expression of genes located within $\mathrm{CpG}$ islands (34). CpG-binding protein plays a crucial role in embryo viability and peri-implantation development. Mouse embryos lacking the $C g b p$ gene are viable only up to the blastocyst stage. These results illustrate loss of methylation control rarely in preimplantation development lead to abnormal development and cell death (35).

Several human genetic diseases have been found to be due to mutations in genes that produce proteins that are known or suspected to be involved in maintaining or modifying DNA methylation (36) (Table 1). The spectrum of mutations identified in patients with immunodeficiency, centromeric instability and facial anomalies (ICF), predominantly missense mutations in the C-terminal catalytic domain of DNMT3B gene located at chromosome 20q11.2, interfere with but not to completely abolish the methyltransferase enzymatic activity (37). The syndrome is a rare autosomal recessive disorder in which patients display immunodeficiency; instability of pericentromeric heterochromatin of chromosomes 1, 9, and 16; and facial anomalies, as well as mental retardation and developmental delay (38). Satellite DNA at pericentromeric heterochromatin 
Table 1. Epigenetic disorders due to methylation and/or acetylation defects

\begin{tabular}{|c|c|c|c|}
\hline Defective gene & Effect & Syndrome & Reference \\
\hline DNMT3B gene & $\begin{array}{l}\text { Pericentromeric } \\
\text { Hypomethylation }\end{array}$ & $\begin{array}{l}\text { (ICF) Immunodeficiency } \\
\text { Centromeric instability } \\
\text { Facial anomalies }\end{array}$ & 39 \\
\hline MECP2 gene & $\begin{array}{l}\text { Hyperacetylated } \\
\text { Histones }\end{array}$ & $\begin{array}{l}\text { Rett syndrome } \\
\text { X linked dominant } \\
\text { MR, loss of motor } \\
\text { Function }\end{array}$ & $\begin{array}{r}112 \\
33\end{array}$ \\
\hline MECP2 gene & & $\begin{array}{l}\text { Non-specific } \\
\text { X linked MR }\end{array}$ & 44 \\
\hline MECP2 gene & & $\begin{array}{l}\text { PPM-X syndrome } \\
\text { Psychosis, Pyramidal signs } \\
\text { Macro-orchidism }\end{array}$ & 45 \\
\hline FMRI gene & $\begin{array}{l}\text { De novo methylation } \\
\text { Histone acetylation } \\
\text { Of CGG repeats }\end{array}$ & $\begin{array}{l}\text { Fragile X mental } \\
\text { Retardation }\end{array}$ & $\begin{array}{l}46 \\
47\end{array}$ \\
\hline ATRX gene & $\begin{array}{l}\text { DNA methylation } \\
\text { Abnormalities in } \\
\text { Heterochromatic } \\
\text { Regions. }\end{array}$ & $\begin{array}{l}\text { ATR-X, X linked } \\
\text { alpha thalassemia } \\
\text { Mental retardation } \\
\text { Syndrome }\end{array}$ & 48 \\
\hline $\mathrm{CBP}$ & $\begin{array}{l}\text { Acetylation defect } \\
\text { In promoter } \\
\text { Nucleosomes }\end{array}$ & $\begin{array}{l}\text { Rubinstein-Taybi } \\
\text { syndrome (RTS) }\end{array}$ & $\begin{array}{r}113 \\
50\end{array}$ \\
\hline
\end{tabular}

is hypomethylated in patients with ICF syndrome (39). Mutations in genes that code for methyl-CpG binding proteins MECP2, MBD1, and MBD2 could induce hyperacetylation of histones (33) and prevent transcriptional repression of methylated DNA (40) as seen in Rett syndrome (RTT), which is caused by mutations in the gene at Xq28 that encodes MECP2 (41). Patients with classical RTT seem to develop normally for 6-18 mo; however, this is followed by a period of regression characterized by a deceleration in head growth, loss of speech and purposeful hand use, and the appearance of repetitive hand movements. Patients can also suffer from autism, apraxia, and severe breathing dysfunction (42). After this initial period of regression, the condition becomes more stable and many survive into adulthood. Because $M E C P 2$ is on the $\mathrm{X}$ chromosome, $\mathrm{X}$ inactivation patterns play a significant role in determining the severity of symptoms. RTT is now known to be one of the most predominant causes of mental retardation in female individuals, occurring with a frequency of up to $1 / 10,000$ live female births (43). Mutations in male individuals are thought to be lethal, but cases of severe neonatal encephalopathy have been reported in male individuals born in RTT families (44). Mutations at seven different sites on MECP2 gene have been identified. Mutations in the same gene but distinct from those involved in RTT have been identified as the cause of nonspecific X-linked mental retardation (45). Another A140V mutation on $M E C P 2$ gene is the cause of the $\mathrm{X}$-linked syndrome of psychosis, pyramidal signs, and macro-orchidism in affected male individuals and female carriers (46). De novo methylation and histone acetylation of the expanded polymorphic CGG repeats (50 to $>200$ times) in the 5 ' region of fragile $X$ mental retardation gene 1 (FMRI) located at Xq27.3 cause fragile $\mathrm{X}$ mental retardation. FMRI gene codes for FMR1 protein, which regulates synaptic plasticity, important in learning and memory (47). The de novo methylation spreads to the $\mathrm{CpG}$ island in the promoter region and silence the FMR1 gene and thus FMR1 protein transcription. Children with X-linked $\alpha$-thalassemia/ mental retardation (ATRX) display mental retardation, hypotonia, developmental delays, craniofacial anomalies, $\alpha$-thalassemia, and urogenital abnormalities. The ATRX gene located at $X$ q13 encodes chromatin-remodeling proteins that are critical mediators of cell survival during early neuronal differentiation (48). Mutations in ATRX gene cause changes in the methylation patterns of repeated sequences (49). Mutation of the cAMP response element binding (CREB) protein, a histone acetyltransferase, is the cause of Rubinstein-Taybi syndrome (RTS) (50).

CREB protein belongs to a large family of structurally related transcription factors that recognize the cAMP response promoter site (5'-TGACGTCA-3') and enhance transcription by acetylating histones in promoter nucleosomes (51). RTS is characterized by mental retardation, short stature, broad thumbs and toes, and facial anomalies. Mouse RTS model studies suggest that treatment with drugs, such as phosphodiesterase 4, that modulate CREB function by enhancing cAMP signaling could abolish long-term memory defect (52). A common feature of the above diseases is mental retardation. It seems that early neuronal development is transcriptionally regulated by genes involved in DNA epigenetic regulation (53).

Besides mutations in DNMTs, methylation defects may arise from epigenetic alterations of the genes of interest. In addition, altered expression of DNMTs during the cell cycle may lead to methylation defects. DNMT1 and $3 b$ levels were found to be significantly down-regulated in G0/G1 phase, whereas DNMT3a mRNA levels were less sensitive to cell-cycle alterations and were maintained at a slightly higher level in tumor lines compared with normal cells (54). Similarly, changes in embryo or oocyte developmental timing, such as may be caused by in vitro culture, may interfere with DNMT activity and result in altered methylation patterns and expression levels.

Imprinting disorders. Most autosomal genes are expressed from both maternal and paternal alleles. However, imprinted genes are an example of non-Mendelian genetics, in which only one member of the gene pair is expressed and expression is determined by the parent of origin (55). Imprinted genes may account for $0.1-1 \%$ of all mammalian genes. At least 80 imprinted genes have been identified in humans, and imprinted genes frequently cluster under the control of an imprinting center. Genome imprinting, although observed in species such as Drosophila melanogaster (chromatin remodeling proteins), Neurospora Crassa (X chromosome inactivation), and flowering plants (55), have evolved to complex levels to fine-tune growth of the fetus in marsupials (56) and eutherian mammals. Imprinting is epigenetically controlled. Although DNA methylation has a crucial role in the process as evidenced by differential methylation of gametes in highly methylated domains within or near the imprinted genes (57), other processes such as exclusive histone acetylation of expressed allele (IGF2H19, IGF2r, Snrpn, and U2af1-rs1), antisense transcripts (KCNQ1/KCNQ10T1 and UBE3A/UBE3A-AS), and the presence of repeat elements near or within the differential methylated domains (IGF2r DMD2) are also involved (58). Genes 
that are regulated by imprinting have been shown to be essential for fetal growth (IGF2r, Cdkn1c, H19/IGF2, Gnas, Peg 1, Peg 3 Ins2, Kcnq1ot1, Ndn, and Rasgrf1), placental function (Slc22a3, H19/IGF2, Peg1, Peg 3, Ascl2, and Tssc3), neurologic development (Kcnq1, Ube3a, Peg1, Peg 3, Ndn, Snrpn, and Nnat), and carcinogenesis (IGF2, WT1, M6P/IGF2R, and p73) (59). Mutations in these genes are associated with several human syndromes, including Silver-Russell (chromosome 7), Albright hereditary dystrophy (chromosome 20), Prader-Willi/ Angelman (chromosome 15), Beckwith-Wiedemann (chromosome 11), and Wilms' tumor. Altered imprinting is also suspected in other neurobehavioral disorders such as autism, epilepsy, Tourette syndrome, late-onset Alzheimer's, schizophrenia, and bipolar affective disorders (60). Mouse knockouts of some imprinted genes show significant neurologic defects ranging from abnormal maternal behavior (Peg3 and Pegl) and impaired memory (Grfl and Gabrb3) to motor dysfunction with seizures (Ube3a).

Germ cell development and preimplantation embryogenesis are crucial windows in erasure, acquisition, and maintenance of genomic imprints. A complete defect of imprint erasure would result in $50 \%$ of the gametes maintaining an inappropriate imprint and carrying the opposite sex's epigenotype at certain imprinted loci. Establishment defects could result in absence of an imprint at a specific locus and again lead to the gametes' harboring the opposite sex's imprint epigenotype. Defects in imprint maintenance could occur at any stage of pre- or postimplantation embryo development. Maintenance defects in postzygotic embryos could lead to mosaicism with a subset of cells affected by the maintenance defect and the remainder of cells unaffected (i.e. with normal imprints). The timing of imprinting is also crucial, as disturbances between embryonic clock and imprinting could cause major disturbances and could be the postulated cause for increased methylation defects in infants who were conceived with the use of ART. For example, DNMT1o is essential for the maintenance of methylation on imprinted genes in mouse 8 cell stage embryo, at which time the normally cytoplasmic isoform translocates to the nucleus. Embryos that are absent of DNMT1o implant successfully but die before birth (30).

Angelman syndrome (AS) and Prader-Willi syndrome (PWS) were initially described in the 1950s and 1960s and are associated with deletion at 15 q11-13, which harbors a cluster of imprinted genes including SNRPN, UBE3A, ZNF127, IPW, and NDN (Table 2). The characteristic features of AS include severe developmental delay, absent speech, seizures, ataxia, hyperreflexia, and hypotonia. Approximately $70 \%$ of cases of AS arise from a deletion of the maternal homologue of chromosome 15q11-13, including UBE3A85, a gene normally expressed from the maternal allele. Ten percent of patients with AS have point mutations involving the maternal allele of $U B E 3 A$ (61). Ube $3 a / U B E 3 A$ shows tissue-specific imprinting, being biallelically expressed in most tissues with the paternal allele silenced selectively in hippocampal and cerebellar neurons. AS arises infrequently from paternal UPD for chromosome 15 (62). In addition, $4 \%$ of patients with AS have a maternally inherited microdeletion of an imprinting control center that is normally methylated on $15 \mathrm{q}$ (63) and lies proximal to SNRPN or have epigenetic alterations to this locus, leading to abnormal hypomethylation of the chromosome. PWS is associated with loss of function of the paternal allele or maternal duplication of the SNRPN imprinting locus on 15p11-13. It is characterized by muscular hypotonia, obesity, mental retardation, and hypogonadotrophic hypogonadism and characteristic reduced fetal activity in utero. In a subset of patients with PWS, paternally inherited microdeletion near exon 1 of $S N R P N$ resulting in methylation at the imprinting control center, which causes loss of function of paternally expressed genes in this locus, is seen.

Another disease associated with epigenetic changes is BWS. These alterations occur on the maternal allele at $11 \mathrm{p} 15.5$, which contains imprinted genes H19, IGF2, CDKN1C (p57KIP2), KCNQ1, and KCNQ1OT1 (LIT1). BWS is characterized by prenatal overgrowth, abdominal wall defects (exomphalos, omphalocele, or umbilical hernia), neonatal hypoglycemia, visceromegaly, macroglossia, characteristic indentations of the ear, placentomegaly, and placental chorioangioma. Children with BWS are at an increased risk for developing embryonal tumors, including Wilms' tumor and hepatoblastoma. Two different methylation defects or LOI have been described in patients with BWS. LOI at BWS imprinting center 2 (BWSIC2) involving KCNQ1OT1 (LIT1), the antisense transcript of KCNQ1, is seen in $40 \%$ of patients with BWS. Expression of KCNQ1OT1 (usually expressed from paternal allele) becomes biallelic, whereas CDKN1C and KCQ1 are silenced $(64,65)$. BWSIC2 LOI seems to be specifically associated with birth defects, including prenatal overgrowth and midline abdominal wall defects, such as omphalocele (66). Another $15 \%$ of BWS cases involve imprinting defects of BWSIC1, resulting in gain in methylation of H19 DMD on maternal alleles. As a result, the maternal allele of $H 19$ is silenced, whereas the maternal allele of IGF2 is abnor-

Table 2. Epigenetic disorders due to imprinting defects

\begin{tabular}{|c|c|c|c|}
\hline Defective gene & Effect & Syndrome & Reference \\
\hline $15 q 11-13$ deletion & Ubiquitin protein ligase defect & AS $(70 \%)$ & Knoll et al 1989 (113) \\
\hline UBE3A point mutation & & AS $(10 \%)$ & Kishino et al 1997 (61) \\
\hline Microdeletion $15 q$ & ICC defect & $\mathrm{AS}(4 \%)$ & Buiting et al 1995 (63) \\
\hline Uniparental disomy (chromosome 15) & & AS & Malcolm et al 1991 (62) \\
\hline SNRPN IC & Methylation & PWS & \\
\hline BWSIC2 (L1T1) & Hypomethylation & BWS $(40 \%)$ & DeBaun et al 2003 (95) \\
\hline BWSIC1 (H19/IGF2) & Hypermethylation & BWS (15\%) & DeBaun et al 2002 (66) \\
\hline CDKN1C (P57kip2) & Kinase Inhibitor deactivation & BWS $(5 \%)$ & \\
\hline Uniparental disomy (11p15 region) & & BWS $(10 \%)$ & \\
\hline
\end{tabular}


mally activated, causing biallelic expression. This epigenetic alteration is associated specifically with increased cancer risk in patients with BWS (66). Approximately $5 \%$ of BWS cases involve conventional null mutations in the maternal allele of CDKN1C. In addition, approximately $10 \%$ of patients with BWS have paternal UPD for the entire $11 \mathrm{p} 15$ region, including H19, IGF2, CDKN1C, KCNQ1, and KCNQ1OT1. There is increased frequency of monozygotic twinning among patients with BWS (67), with the affected twin showing LOI and biallelic expression of KCNQ1OT1. Unequal splitting of inner cell mass resulting in mosaicism for the BWS defect or an imprinting defect during preimplantation stage causing a problem with imprint maintenance at KCNQ1OT1 is postulated.

UPD disorders. UPD that arises spontaneously has been well documented in humans and causes birth defects when imprinted genes are affected (68). It occurs when both homologues of a chromosome are inherited from one parent, generating a diploid chromosome number but an imbalance in maternally and paternally inherited genes. Another cause for UPD is mosaicism as a result of postzygotic somatic segregation errors (69). Embryos that possess two maternal genomes form teratomas, whereas embryos that possess two paternal genomes form trophoblastic tumors. Teratomas may arise from parthenogenetic activation of an unfertilized oocyte within the ovary and may contain several types of differentiated tissues but no extraembryonic tissue. In gestational trophoblastic tumors, including hydatidiform mole, there is hyperplasia of extraembryonic tissue with lack of embryo development. They arise from fertilization of enucleated egg or develop after loss of maternal chromosome from the embryo and develop into completed mole with only two paternal sets of chromosomes (andogenetic) or partial mole with triploidy (two paternal and one maternal set of chromosomes). Recently, completed mole with biparental origin has been reported and is associated with global disruption of maternal imprinting, likely occurring during oocyte development (70). There is LOI in the normal maternally methylated genes (KCNQ1OT1, SNRPN, PEG1, and $P E G 3$ ) and a recessive maternal effect mutation causing the maternal genome to assume the paternal epigenetic appearance. Silver-Russell syndrome is thought to be caused by maternal UPD of a region on chromosome 7 . The syndrome is characterized by low birth weight, dwarfism, and lateral asymmetry (71).

Epigenetic disorders and childhood cancers. Recently, multiple pieces of evidence are emerging associating epigenetic disorders with childhood and adult cancers (72). Both methylation and imprinting defects are implicated. DNA methylation is one mechanism by which cancer cells switch off the expression of different tumor suppressor genes, thus allowing the cancer cells to escape normal growth control mechanisms. Wilms' tumor is the most common childhood kidney tumor. Recent studies suggest that in 54\% of cases, the tumor suppressor gene RASSF1A in the 3p21-3 region is hypermethylated, whereas in $10 \%$, p16 promotor gene is methylated (73). LOI at IGF2/H19 locus (BWSIC2) is noted in Wilms' tumor, occurs very early in development, and is seen in kidney tissue adjacent to the tumor (74). In embryonal rhabdomyosarcoma, silencing of the active copy of imprinted gene $\mathrm{H} 19$ occurs by methylation (75). Hypermethylation of cell regulatory gene p15 (INK4b) has been shown in acute myeloid leukemia and myelodysplastic syndrome (76). In retinoblastoma (RB), another early childhood tumor of the retina, the $R B 1$ gene is epigenetically silenced by hypermethylation of the promoter region and exon 1 (77) and results in reduced $R B 1$ expression (78). Differential methylation of chromosome $13 q$ around the $R B 1$ gene (79) and the preferential loss of maternal alleles in certain sporadic cases of RB suggest latent or aberrant imprinting in these individuals. Ohtani-Fujita et al. (80) determined that the frequency of hypermethylation in unilateral tumors is $9 \%$ (13 of 140), whereas the frequency was only $1 \%$ in hereditary bilateral tumors ( 1 of 101). Neurofibromatosis type 1 (NFI) is a common autosomal dominant disorder characterized by cafe-au-lait spots, neurofibromas, and iris hamartomas. The NF1 gene is involved in the down-regulation of p21 (ras) oncogenes and is hypermethylated in NF1, thus promoting tumorigenesis (81). Epigenetic alterations are also observed in adult cancers. Methylation defects are noted in renal cell carcinoma ( $G 250$ promoter gene and 3p21.3 suppressor gene), personal and familial colorectal cancer including hereditary nonpolyposis colon cancer (RASSF1A gene and GATA-4 and GATA-5 gene), and breast and gastric cancers (TMS1 gene).

\section{INTERFERENCE OF EPIGENETIC PROGRAMMING BY ART}

Culture media and low birth weight and LOS. There are concerns that epigenetic alterations could be caused by ART involving gamete and embryo culture and manipulation $(82,83)$. Numerous studies suggest that singleton infants who are born out of ART are at increased risk for low birth weight (LBW), very low birth weight (VLBW), preterm delivery, and fetal growth restriction in comparison with naturally conceived infants. These include population-based studies that compared infants who were conceived with the use of ART with expected rates for various outcomes in the countries from which the ART samples were drawn (84) and well-designed analyses from clinical settings in which ART singletons were compared with non-ART control groups $(85,86)$. Schieve et al. (3) recently reported that singletons who were born after ART in the United States had nearly twice the risk for LBW and VLBW as expected on the basis of rates for singleton births to nonteen mothers in the general U.S. population during the same period. Although there was some variation, the increased risks for both LBW and VLBW were observed for all infertility diagnoses subsets. In addition, the risks remained elevated after restricting analyses to subgroups that were conceived with presumably healthy gametes (oocytes from an egg donor and sperm from a partner without a diagnosis of male-factor infertility) or carried by a presumably healthy woman (no female infertility diagnoses reported; ART used because of male-factor infertility). Similar reduction in birth weight was observed in mice and was associated with decreased expression of H19 and IGF2 and increased methylation of H19 DMD (87), whereas in cattle and sheep, several reports have described an enhancement in fetal growth referred to as the large offspring syndrome (LOS) (88) with an increase of $\sim 8-50 \%$ from mean control weight 
(89). LOS is characterized by a significant increase in birth weight, increased gestational length, breathing problems at birth, and increased frequency of perinatal death. LOS can arise after embryo culture, asynchronous transfer, and maternal diet rich in urea and after nuclear transfer cloning. All culture systems associated with LOS contain sera or are coculture with support cells, such as granulosa cells, oviductal cells, or fibroblasts, and may play a role in epigenetic alterations (90). In sheep with LOS, lack of expression and aberrant methylation of IGF2R has been reported (91). The IGF2R locus is imprinted in mice, sheep, cows, and pigs but not in humans. Similarly in BWS and AS, both associated with ART, there is loss of function of maternal alleles and duplication of paternal alleles at different imprinted loci. This suggests that maternal genome is more vulnerable than paternal genome to imprinting or methylation defects when exposed to culture media as part of ART. Possible explanation for increased sensitivity of maternal genome is that the majority of imprinted genes are regulated by maternally derived methylation imprint, whereas only a few imprinted genes (H19, RASGRF1, and GTL2) are paternally inherited. Second, there is rapid and active demethylation of paternal genome within hours of fertilization, thus resulting in less exposure of paternally imprinted genes to culture media, compared with maternal genome, which is demethylated by a slow, passive process, thus allowing exposure to components of the culture media for a longer duration.

Components in culture media could also affect the methylation pattern. Addition of FCS to M16 medium caused mouse pups to be lower in weight compared with control and exhibited decreased H19 and IGF2 expression (87). Similarly, mouse blastocysts that were exposed to Whitten's medium led to aberrant expression of the normally silent paternal allele of $\mathrm{H} 19$, but those that were cultured in KSOM with amino acids showed no sign of aberrant H19 expression or methylation (92). This suggests that media components could remove or interact with methyl groups on DNA or on histone tails and cause methylation defects. The critical difference between culture media is their methionine content, which can affect DNA methylation and imprinting $(93,94)$. Alternatively the culture media could alter the embryonic developmental timing and could cause epigenetic disturbances, especially when prolonged use of culture media is used as in blastocyst culture for IVF cycles in which preimplantation genetic diagnosis is used. However, there was no difference in birth weight noted after blastocyst transfers compared with cleavage-stage embryo transfers (95).

ART and imprinting disorders. Concerns of epigenetic disturbances caused by culture media in animal studies led to studies that examined similar defects in children who were conceived with ART. The first study by Manning et al. (96) to determine abnormal methylation at 15q11-13 (linked to AS and PWS) in ICSI did not show any defect or any clinical syndrome in the children conceived. More recently, however, five studies reported a possible association between ART and BWS (97-99), AS (100,101), and RB (102). DeBaun et al. (97) screened a combined National Registry of BWS patients and detected seven children with BWS after ART. When they were examined for imprinting disorders, DeBaun et al. determined that four had spontaneous imprinting changes in the LIT1 subdomain and one had changes at both LIT1 and IGF2-H19 subdomains. In this same study, they determined a prevalence of $4.6 \%$ ( 3 of 65 ) in their registry when compared with the general population of $0.76 \%$ during the same period in the United States. Maher et al. (98) also examined a chart of 149 sporadic BWS births and detected six (4\%) patients whose parents had used one ART to conceive, compared with a background rate of $0.997 \%$ in the United Kingdom. Similar to DeBaun et al. (97), two of the patients who were examined molecularly had hypomethylation of LIT1. Finally, in a third study, Gicquel et al. (99) used a registry of 149 patients with BWS to identify six patients with BWS born after ART. In the total 19 cases of BWS, 13 had KCNQ1OT1 (LIT1) hypomethylation (BWSIC2 defect) and one had H19 hypermethylation (BWSIC1 defect). One patient with BWS had normal methylation for H19 and KCNQ1OT1. On the basis of the above studies, assuming that $1 \%$ of all children are born as a result of ART, a 4-fold increase in the incidence of BWS is observed with ART.

In a recent review of the national BWS registry used in the study by DeBaun and colleagues (103), 19 children with BWS were born after ART. Clinical data from the IVF clinics were available for 12 sets of parents. There was no difference between children who had BWS and were born after ART in BWS phenotype, type of ART, ovulation induction protocol, cause of infertility of parents, day of embryo/blastocyst transfer, and the type of culture media used. The only common feature among the group was the use of ovarian stimulation medication. The authors summarized that, with the exception of receiving ovarian stimulation medication either as part of IVF or to facilitate conception, no common factor was identified among the women who gave birth to children with BWS, although the study was limited by small sample size.

Cox et al. (100) identified two and Orstavik et al. (101) identified a third child with AS who were conceived by ICSI. In all three, analysis of the 15q11-13 locus revealed loss of methylation on the maternal allele for SNRPN. Their parents had normal methylation, and the children had no chromosomal deletion at the locus. A casual relationship between ICSI and $\mathrm{AS}$ as a result of imprinting disorder is likely based on the rare one in 15,000 incidence of AS in the general population. Moll et al. (102) reported five cases of RB in children who were conceived by IVF in the Netherlands. The authors estimated that the incidence of RB in the Netherlands is $1 / 17,000$ live births. They concluded that, assuming that $1 \%$ of all children are born as a result of ART, there was a 4-fold increase in the incidence of RB with ART.

Use of immature gametes for ART. There are concerns about reproductive outcome when immature gametes were used for ART, especially the use of round spermatids obtained after epididymal or testicular aspiration procedures $(104,105)$. Of utmost concern was the transmission of gene mutations related to spermatogenesis (e.g. $A Z F c, D A Z$ gene) into the offspring, which was the primary cause of infertility in the parent. Immature sperm cells have an epigenetically distinct imprinting status. However, by the spermatid phase of spermiogenesis, imprinting is largely completed as shown by 
mouse studies confirming imprinting of paternally expressed Snrpn, Igf-2, and Pegl and the maternally expressed Mash2, $I g f-2 r$, and $H 19$ by spermatid stage (106). Hence, it is unlikely that ART involving male gametes interferes with either erasure or acquisition of imprints, but it is reported that in men with spermiogenesis anomalies, abnormal DNA packaging is observed as a result of a lack of exchange of histone with protamines, resulting in problems with chromatin remodeling, abnormal DNA methylation, and increased sensitivity of DNA to damage (107). The lack of chromatin condensation in immature sperm cells can cause delayed oocyte activation, which could cause aneuploidy in the embryo. Moreover, the methylation patterns of spermatids and sperm derived from testes and epididymis differ from the hypermethylated patterns found in ejaculated sperm (108). Hence, use of immature sperm for ART could increase the risk for an imprinting disorder or malformation (105), although large-scale studies did not show increased risk for malformations (109). The use of round spermatids in ICSI could interfere with mouse embryo preimplantation epigenetic reprogramming, less efficient genome activation, and a higher rate of developmental arrest compared with ICSI with mature sperm. The increased embryo developmental arrest suggests that mechanisms exist in the embryo to arrest aberrant spermatid transcription. Another potential concern is that disturbances in imprinting could occur during sperm and embryo freezing. Cryopreservation potentially could affect the cytoskeleton and the availability of enzymes such as DNMT, which maintain methylation of imprinted loci during the preimplantation phase.

Oocyte maturation in vitro is associated with loss of developmental competence (110), unless the oocyte is near completion of its preovulatory growth phase. This loss of developmental competence is associated with the absence of specific proteins in oocytes cultured to metaphase II in vitro and loss of methylation at IGF2R and PEG1 and methylation at H19 (111). Their subsequent embryonic development seems to be severely compromised $(78,79)$ and may be attributable to suboptimal culture conditions, incomplete oocyte growth, or abnormal cytoplasmic maturation $(79,112,113)$.

\section{CONCLUSIONS}

There is convincing evidence to show that normal embryogenesis cannot occur without epigenetic regulation, which is also critical during gametogenesis. These processes involve DNA methylation, imprinting, RNA silencing, covalent modifications of histones, and remodeling by other chromatinassociated complexes. Epigenetic reprogramming during gametogenesis is essential for imprinting, which regulates the differential expression of paternally and maternally derived genes in the embryo by escaping the general (de)methylation processes at the preimplantation stage. Reprogramming during the preimplantation period is essential for early embryo development as it controls the expression of early embryonic genes, cell cleavage, and cell determination.

Failure or incomplete epigenetic reprogramming at the gamete and preimplantation stages may lead to developmental problems and early mortality. Unlike genetic modifications, some epigenetic alterations may be tolerated during development and are usually reversible as a result of erasure in the germ line. Incomplete erasure results in epigenetic inheritance. Another way for epigenetic inheritance to occur is when these changes occur after fertilization but before specification of the germ line. This may manifest as increased perinatal mortality and LBW as observed in the children of women who were not underweight at birth but were malnourished in the first and second trimesters of their own fetal development during the Dutch famine of 1944-1945.

DNA methylation is a major mechanism by which epigenetic regulation occurs in gametes and embryos, and the maintenance of methylation patterns on DNA depends on DNMT1, DNMT2, DNMT3a, DNMT3b and the isoform of DNMT1, DNMT1o, which provides maintenance methyltransferase activity specifically at imprinted loci during the fourth embryonic $S$ phase. Several genetic diseases have been associated with DNA methylation defects, including ICF, RTT, X-linked dominant mental retardation, nonspecific X-linked mental retardation, and ATRX (Table 1). Imprinting disorders can cause epigenetic alterations and may be due to gene defects (LIT 1, $H 19, I G F 2, U B E 3 A$, and $R B 1$ ), deletions (15q-13), or UPD. Conceptuses with UPD have poor embryonic development. Embryos that possess two paternal genomes form trophoblastic tumors, whereas embryos that possess two maternal genomes form teratomas.

Recent reports suggest the increased incidence of imprinting disorders such as BWS, AS, and RB in children who are conceived with the use of ART and may result from an accumulation of epigenetic alterations during embryo culture and/or by altered embryonic developmental timing. It is interesting to note that most (not all) of these ART-associated imprinting disorders involve the maternal allele, suggesting that ART effects are greater on the oocytes than on the sperm, although the data are limited. On the basis of the available data, although limited, there is a 4-fold increase in the incidence of imprinting disorders with ART. Also, it may be suggested that there is increased relative risk for childhood cancers, such as RB, with ART. Moreover, BWSIC2 defect is associated with Wilms' tumor. The use of immature oocytes and spermatids in ART may induce epigenetic programming defects and cause increased developmental arrest in the embryos.

Numerous studies suggest that singleton infants who are born out of ART are at increased risk for LBW, VLBW, preterm delivery, and fetal growth restriction in comparison with naturally conceived infants, whereas in cattle and sheep, several reports have described an enhancement in fetal growth with an increase of $\sim 8-50 \%$ from mean control weight referred to as the LOS. Although the exact mechanism by which ART cause these changes are unknown, culture media components (e.g. sera, methionine) that could interact with methyl groups on DNA or histone tails and cause epigenetic modifications are implicated. Another explanation may be that embryonic developmental timing is disturbed by the culture media. Clear evidence of such an association and elucidation of a cause needs to be determined by large, extensive, prospective studies over several years with molecular and biologic evaluations. 


\section{REFERENCES}

1. Hansen RS, Wijmenga C, Luo P, Stanek AM, Canfield TK, Weemaes CM, Gartler SM 1999 The DNMT3B DNA methyltransferase gene is mutated in the ICF immunodeficiency syndrome. Proc Natl Acad Sci USA 96:14412-14417

2. Anthony S, Buitendijk SE, Dorrepaal CA, Lindner K, Braat DD, den Ouden AL 2002 Congenital malformations in 4224 children conceived after IVF. Hum Reprod 17:2089-2095

3. Schieve LA, Meikle SF, Ferre C, Peterson HB, Jeng G, Wilcox LS 2002 Low and very low birth weight in infants conceived with use of assisted reproductive technology. N Engl J Med 346:731-737

4. Klemetti R, Gissler M, Hemminki E 2002 Comparison of perinatal health of children born from IVF in Finland in the early and late 1990s. Hum Reprod 17:2192-2198

5. 1990 Births in Great Britain resulting from assisted conception, 1978-87. MRC Working Party on Children Conceived by In Vitro Fertilisation. BMJ 300:12291233

6. Reik W, Dean W, Walter J 2001 Epigenetic reprogramming in mammalian development. Science 293:1089-1093

7. Hajkova P, Erhardt S, Lane N, Haaf T, El-Maarri O, Reik W, Walter J, Surani MA 2002 Epigenetic reprogramming in mouse primordial germ cells. Mech Dev 117:15-23

8. Yamazaki Y, Mann MR, Lee SS, Marh J, McCarrey JR, Yanagimachi R, Bartolome MS 2003 Reprogramming of primordial germ cells begins before migration into the genital ridge, making these cells inadequate donors for reproductive cloning. Proc Natl Acad Sci USA 100:12207-12212

9. Obata Y, Kono T 2002 Maternal primary imprinting is established at a specific time for each gene throughout oocyte growth. J Biol Chem 277:5285-5289

0. Davis TL, Yang GJ, McCarrey JR, Bartolomei MS 2000 The H19 methylation imprint is erased and re-established differentially on the parental alleles during male germ cell development. Hum Mol Genet 9:2885-2894

11. Mayer W, Niveleau A, Walter, Fundele R, Haaf T 2000 Demethylation of the zygotic paternal genome. Nature 403:501-502

12. Santos F, Hendrich B, Reik W, Dean W 2002 Dynamic reprogramming of DNA methylation in the early mouse embryo. Dev Biol 241:172-182

13. Tremblay KD, Duran KL, Bartolomei MS 1997 A 5'2-kilobase-pair region of the imprinted mouse H19 gene exhibits exclusive paternal methylation throughout development. Mol Cell Biol 17:4322-4329

14. Rossant J, Sanford JP, Chapman VM, Andrews GK 1986 Undermethylation of structural gene sequences in extraembryonic lineages of the mouse. Dev Biol 117:567-573

15. Morgan HD, Sutherland HG, Martin DI, Whitelaw E 1999 Epigenetic inheritance at the agouti locus in the mouse. Nat Genet 23 314-318

16. John RM, Surani MA 1999 Agouti germ line gets acquisitive. Nat Genet 23:314318

17. Silva AJ, White R 1988 Inheritance of allelic blueprints for methylation patterns. Cell 54:145-152

18. Roemer I, Reik W, Dean W, Klose J 1997 Epigenetic inheritance in the mouse. Curr Biol 7:277-280

19. Lumey LH 1992 Decreased birthweights in infants after maternal in utero exposure to the Dutch famine of 1944-1945. Paediatr Perinat Epidemiol 6:240-253

20. Li E, Bestor TH, Jaenisch R 1992 Targeted mutation of the DNA methyltransferase gene results in embryonic lethality. Cell 69:915-926

21. Okano M, Bell DW, Haber DA, Li E 1999 DNA methyltransferases Dnmt3a and Dnmt3b are essential for de novo methylation and mammalian development. Cell 99:247-257

22. Bourc'his D, Xu GL, Lin CS, Bollman B, Bestor TH 2001 Dnmt3L and the establishment of maternal genomic imprints. Science 294:2536-2539

23. McGrath J, Solter D 1984 Completion of mouse embryogenesis requires both the maternal and paternal genomes. Cell 37:179-183

24. Bourc'his D, Le Bourhis D, Patin D, Niveleau A, Comizzoli P, Renard JP, Viegas-Péquignot E 2001 Delayed and incomplete reprogramming of chromosome methylation patterns in bovine cloned embryos. Curr Biol 11:1542-1546

25. Cattanach BM, Kirk M 1985 Differential activity of maternally and paternally derived chromosome regions in mice. Nature 315:496-498

26. Young LE 2001 Imprinting of genes and the Barker hypothesis. Twin Res 4:307 317

27. DeChiara TM, Robertson EJ, Efstratiadis A 1991 Parental imprinting of the mouse insulin-like growth factor II gene. Cell 64:849-859

28. Sun FL, Dean WL, Kelsey G, Allen ND, Reik W 1997 Transactivation of Igf2 in a mouse model of Beckwith-Wiedemann syndrome. Nature 389:809-815

29. Moore T, Haig D 1991 Genomic imprinting in mammalian development: a parental tug-of-war. Trends Genet 7:45-49

30. Dong A, Yoder JA, Zhou L, Xing Z, Bestor TH, Cheng X 2001 Structure of human DNMT2, an enigmatic DNA methyltransferase homologue that displays denaturantresistant binding to DNA. Nucleic Acids Res 29:439-448

31. Okano M, Bell DW, Haber DA, Li E 1999 DNA methyltransferases Dnmt3a and Dnmt3b are essential for de novo methylation and mammalian development. Cell 99:247-257

32. Howell CY, Bestor TH, Ding F, Latham KE, Mertineit C, Trasier JM, Chaillet JR 2001 Genomic imprinting disrupted by a maternal effect mutation in the Dnmt1 gene. Cell 104:829-838

33. Wan M, Zhao K, Lee SS, Francke U 2001 MECP2 truncating mutations cause histone H4 hyperacetylation in Rett syndrome. Hum Mol Genet 10:1085-1092

34. Voo KS, Carlone DL, Jacobsen BM Flodin A, Skalnik DG 2000 Cloning of mammalian transcriptional activator that binds unmethylated $\mathrm{CpG}$ motifs and shares a CXXC domain with DNA methyltransferase, human trithorax, and methyl-CpG binding domain protein 1. Mol Cel1 Biol 20:2108-2121

35. Carlone DL, Skalnik DG $2001 \mathrm{CpG}$ binding protein is crucial for early embryonic development. Mol Cell Biol 21:7601-7606

36. Robertson KD, Wolffe AP 2000 DNA methylation in health and disease. Nat Rev Genet 1:11-19

37. Wijmenga C, Hansen RS, Gimelli G, Bjorck EJ, Davies EG, Valentine D, Belohradsky BH, Van Dongen JJ, Smeets DF, Van den Heuvel LP, Luyten JA, Strengman E, Weemaes C, Pearson PL 2000 Genetic variation in ICF syndrome: evidence for genetic heterogeneity. Hum Mutat 16:509-517

38. Hansen RS, Wijmenga C, Luo P, Stanek AM, Canfield TK, Weemaes CM, Gartler SM 1999 The DNMT3B DNA methyltransferase gene is mutated in the ICF immunodeficiency syndrome. Proc Natl Acad Sci USA 96:14412-14417

39. Jeanpierre M, Turleau C, Aurias A, Prieur M, Ledeist F, Fischer A, ViegasPequignot E 1993 An embryonic-like methylation pattern of classical satellite DNA is observed in ICF syndrome. Hum Mol Genet 2:731-735

40. Amir RE, Van den Veyver IB, Wan M, Tran CQ, Francke U, Zoghbi HY 1999 Rett syndrome is caused by mutations in X-linked MECP2, encoding methyl-CpGbinding protein 2. Nat Genet 23:185-188

41. 1988 Diagnostic criteria for Rett syndrome. The Rett Syndrome Diagnostic Criteria Work Group. Ann Neurol 23:425-428

42. Kerr AM, Stephenson JB 1985 Rett's syndrome in the west of Scotland. BMJ (Clin Res Ed) 291:579-582

43. Villard L, Kpebe A, Cardoso C, Chelly PJ, Tardieu PM, Fontes M 2000 Two affected boys in a Rett Syndrome family. Neurology 55:1188-1193

44. Couvert P, Bienvenu T, Aquaviva C, Poirier K, Moraine C, Gendrot C, Verloes A Andres C, Le Fevre AC, Souville I, Steffann J, des Portes V, Ropers HH, Yntema HG, Fryns JP, Briault S, Chelly J, Cherif B 2001 MECP2 is highly mutated in X-linked mental retardation. Hum Mol Genet 10:941-946

45. Klauck SM, Lindsay S, Beyer KS, Splitt M, Burn J, Poustka A 2002 A mutation hot spot for nonspecific X-linked mental retardation in the MECP2 gene causes PPM-X syndrome. Am J Hum Genet 70:1034-1037

46. Oberle I, Rousseau F, Heitz D, Kretz C, Devys D, Hanauer A, Boue J, Bertheas MF, and Mandel JL 1991 Instability of a 550-base pair DNA segment and abnormal methylation in fragile X syndrome. Science 252:1097-1102

47. Verkerk AJ, Pieretti M, Sutcliffe JS, Fu YH, Kuhl DP, Pizzuti A, Reiner O, Richards S, Victoria MF, Zhang FP 1991 Identification of a gene (FMR-1) containing a CGG repeat coincident with a breakpoint cluster region exhibiting length variation in fragile X syndrome. Cell 65:905-914

48. Gibbons RJ, Higgs DR 2000 Molecular-clinical spectrum of the ATR-X syndrome. Am J Med Genet 97:204-212

49. Gibbons RJ, McDowell TL, Raman S, O’Rourke DM, Garrick D, Ayyub H, Higgs DR 2000 Mutations in ATRX, encoding a SWI/SNF-like protein, cause diverse changes in the pattern of DNA methylation. Nat Genet 24:368-371

50. Ogryzko VV, Schiltz RL, Russanova V, Howard BH, Nakatani Y 1996 The transcriptional coactivators p300 and CBP are histone acetyltransferases. Cell 87:953-959

51. Bourtchouladze R, Lidge R, Catapano R, Stanley J, Gossweiler S, Romashko D, Scott R, Tully T 2003 A mouse model of Rubinstein-Taybi syndrome: defective long-term memory is ameliorated by inhibitors of phosphodiesterase 4. Proc Natl Acad Sci USA 100:10518-10522

52. De Rycke M, Liebaers I, Van Steirteghem A 2002 Epigenetic risks related to assisted reproductive technologies. Hum Reprod 17:2487-2494

53. Robertson KD, Keyomarsi K, Gonzales FA, Velicescu M, Jones PA 2000 Differential mRNA expression of the human DNA methyltransferases (DNMTs) 1, 3a, 3b during the $\mathrm{G}(0) / \mathrm{G}(1)$ to $\mathrm{S}$ phase transition in normal and tumor cells. Nucleic Acids Res 28:2108-2113

54. Reik W, Walter J 2001 Genomic imprinting: parental influence on the genome. Nat Rev Genet 2:21-32

55. Spielman M, Vinkenoog R, Dickinson HG, Scott RJ 2001 The epigenetic basis of gender in flowering plants and mammals. Trends Genet 17:705-711

56. Ding F, Patel C, Ratnam S, McCarrey JR, Chaillet JR 2003 Conservation of Dnmt1o cytosine methyltransferase in the marsupial Monodelphus domestica. Genesis 36:209-213

57. Reinhart B, Eljanne M, Chaillet JR 2002 Shared role for differentially methylated domains of imprinted genes. Mol Cell Biol 22:2089-2098

58. Jirtle RL 1999 Genomic imprinting and cancer. Exp Cell Res 248:18-24

59. Falls JG, Pulford DJ, Wylie AA, Jirtle RL 1999 Genomic imprinting: implications for human disease. Am J Pathol 154:635-647

60. Dean W, Ferguson-Smith A 2001 Mother maintains methylation marks. Curr Bio 11:R527-R530

61. Kishino T, Lalande M, Wagstaff J 1997 UBE3A/E6-AP mutations cause Angelman syndrome. Nat Genet 15:70-73

62. Malcolm S, Clayton-Smith J, Nichols M, Robb S, Webb T, Armour JA, Jeffreys AJ, Pembrey ME 1991 Uniparental paternal disomy in Angelman's syndrome. Lancet 337:694-697

63. Buiting K, Saitoh S, Gross S, Dittrich B, Schwartz S, Nicholls RD, Horsthemke B 1995 Inherited microdeletions in the Angelman and Prader-Willi syndromes define an imprinting centre on human chromosome 15. Nat Genet 9:395-400

64. Lee MP, DeBaun MR, Mitsuya K, Galonek HL, Brandenburg S, Oshimura M Feinberg AP 1999 Loss of imprinting of a paternally expressed transcript, with antisense orientation to KVLQT1, occurs frequently in Beckwith-Wiedemann syndrome and is independent of insulin-like growth factor II imprinting. Proc Natl Acad Sci USA 96:5203-5208

65. Smilinich NJ, Day CD, Fitzpatrick GV, Caldwell GM, Lossie AC, Cooper PR, Smallwood AC, Joyce JA, Schofield PN, Reik W, Nicholls RD, Weksberg R, 
Driscoll DJ, Maher ER, Shows TB, Higgins MJ 1999 A maternally methylated CpC island in KvLQT1 is associated with an antisense paternal transcript and loss of imprinting in Beckwith-Wiedemann syndrome. Proc Natl Acad Sci USA 96:80648069

66. DeBaun MR, Niemitz EL, McNeil DE, Brandenburg SA, Lee MP, Feinberg AP 2002 Epigenetic alterations of H19 and LIT1 distinguish patients with BeckwithWiedemann syndrome with cancer and birth defects. Am J Hum Genet 70:604-611

67. Weksberg R, Shuman C, Caluseriu O, Smith AC, Fei YL, Nishikawa J, Stockley TL, Best L, Chitayat D, Olney A, Ives E, Schneider A, Bestor TH, Li M, Sadowski P, Squire J 2002 Discordant KCNQ1OT1 imprinting in sets of monozygotic twins discordant for Beckwith-Wiedemann syndrome. Hum Mol Genet 11:1317-1325

68. Engel E, DeLozier-Blanchet CD 1991 Uniparental disomy, isodisomy, and imprinting: probable effects in man and strategies for their detection. Am J Med Genet 40:432-439

69. Robinson WP, Christian SL, Kuchinka BD, Penaherrera MS, Das S, Schuffenhaue S, Malcolm S, Schinzel AA, Hassold TJ, Ledbetter DH 2000 Somatic segregation errors predominantly contribute to the gain or loss of a paternal chromosome leading to uniparental disomy for chromosome 15. Clin Genet 57:349-358

70. Judson H, Hayward BE, Sheridan E, Bonthron DT 2002 A global disorder of imprinting in the human female germ line. Nature 416:539-542

71. Preece MA 2002 The genetics of the Silver-Russell syndrome. Rev Endocr Metab Disord 3:369-379

72. Feinberg AP, Tycko B 2004 The history of human cancer epigenetics. Nat Rev Cancer 4:143-153

73. Wagner KJ, Cooper WN, Grundy RG, Caldwell G, Jones C, Wadey RB Morton D, Schofield PN, Reik W, Latif F, Maher ER 2002 Frequent RASSF1A tumour suppressor gene promoter methylation in Wilms' tumour and colorectal cancer. Oncogene 21:7277-7282

74. Okamoto K, Morison IM, Taniguchi T, Reeve AE 1997 Epigenetic changes at the insulin-like growth factor II/H19 locus in developing kidney is an early event in Wilms tumorigenesis. Proc Natl Acad Sci USA 94:5367-5371

75. Lynch CA, Tycko B, Bestor TH, Walsh CP 2002 Reactivation of a silenced H19 gene in human rhabdomyosarcoma by demethylation of DNA but not by histone hyperacetylation. Mol Cancer 1:2

76. Tessema M, Langer F, Dingemann J, Ganser A, Kreipe H, Lehmann U 2003 Aberrant methylation and impaired expression of the p15(INK4b) cell cycle regulatory gene in chronic myelomonocytic leukemia (CMML). Leukemia 17:910-918

77. Greger V, Passarge E, Hopping W, Messmer E, Horsthemke B 1989 Epigenetic changes may contribute to the formation and spontaneous regression of retinoblastoma. Hum Genet 83:155-158

78. Moor RM, Dai Y, Lee C, Fulka J Jr 1998 Oocyte maturation and embryonic failure. Hum Reprod Update 4:223-236

79. Kerjean A, Couvert P, Heams T, Chalas C, Poirier K, Chelly J, Jouannet P, Paldi A Poirot C 2003 In vitro follicular growth affects oocyte imprinting establishment in mice. Eur J Hum Genet 11:493-496

80. Ohtani-Fujita N, Dryja TP, Rapaport JM, Fujita T, Matsumura S, Ozasa K, Watanabe Y, Hayashi K, Maeda K, Kinoshita S, Matsumura T, Ohnishi Y, Hotta Y, Takahashi R, Kato MV, Ishizaki K, Sasaki MS, Horsthemke B, Minoda K, Sakai T 1997 Hypermethylation in the retinoblastoma gene is associated with unilateral, sporadic retinoblastoma. Cancer Genet Cytogenet 98:43-49

81. Horan MP, Cooper DN, Upadhyaya M 2000 Hypermethylation of the neurofibromatosis type 1 (NF1) gene promoter is not a common event in the inactivation of the NF1 gene in NF1-specific tumors. Hum Genet 107:33-39

82. Moriai R, Tsuji N, Kobayashi D, Yagihashi A, Namiki Y, Takahashi H, Watanabe N 2002 A proapoptotic caspase recruitment domain protein gene, TMS1, is hypermethylated in human breast and gastric cancers. Anticancer Res 22:4163-4168

83. Gosden R, Trasler J, Lucifero D, Faddy M 2003 Rare congenital disorders, imprinted genes, and assisted reproductive technology. Lancet 361:1975-1977

84. Westergaard HB, Johansen AM, Erb K, Andersen AN 1999 Danish National In-Vitro Fertilization Registry 1994 and 1995: a controlled study of births, malformations and cytogenetic findings. Hum Reprod 14:1896-1902

85. Olivennes F, Rufat P, Andre B, Pourade A, Quiros MC, Frydman R 1993 The increased risk of complication observed in singleton pregnancies resulting from in-vitro fertilization (IVF) does not seem to be related to the IVF method itself. Hum Reprod 8:1297-1300

86. Wang JX, Norman RJ, Kristiansson P 2002 The effect of various infertility treatments on the risk of preterm birth. Hum Reprod 17:945-949

87. Khosla S, Dean W, Reik W, Feil R 2001 Culture of preimplantation embryos and its long-term effects on gene expression and phenotype. Hum Reprod Update 7:419427

88. Sinclair KD, Young LE, Wilmut I, McEvoy TG 2000 In-utero overgrowth in ruminants following embryo culture: lessons from mice and a warning to men. Hum Reprod 15:68-86
89. Young LE, Sinclair KD, Wilmut I 1998 Large offspring syndrome in cattle and sheep. Rev Reprod 3:155-163

90. Young LE, Fairburn HR 2000 Improving the safety of embryo technologies possible role of genomic imprinting. Theriogenology 53:627-648

91. Young LE, Fernandes K, McEvoy TG, Butterwith SC, Gutierrez CG, Carolan C, Broadbent PJ, Robinson JJ, Wilmut I, Sinclair KD 2001 Epigenetic change in IGF2R is associated with fetal overgrowth after sheep embryo culture. Nat Genet 27:153154

92. Doherty AS, Mann MR, Tremblay KD, Bartolomei MS, Schultz RM 2000 Differential effects of culture on imprinted $\mathrm{H} 19$ expression in the preimplantation mouse embryo. Biol Reprod 62:1526-1535

93. Waterland RA, Jirtle RL 2003 Transposable elements: targets for early nutritiona effects on epigenetic gene regulation. Mol Cell Biol 23:5293-5300

94. Wolff GL, Kodell RL, Moore SR, Cooney CA 1998 Maternal epigenetics and methyl supplements affect agouti gene expression in Avy/a mice. FASEB J 12:949-957

95. Menezo YJ, Chouteau J, Torello MJ, Girard A, Veiga A 1999 Birth weight and sex ratio after transfer at the blastocyst stage in humans. Fertil Steril 72:221-224

96. Manning M, Lissens W, Bonduelle M, Camus M, De Rijcke M, Liebaers I, Van Steirteghem A 2000 Study of DNA-methylation patterns at chromosome 15q11-q13 in children born after ICSI reveals no imprinting defects. Mol Hum Reprod 6:1049-1053

97. DeBaun MR, Niemitz EL, Feinberg AP 2003 Association of in vitro fertilization with Beckwith-Wiedemann syndrome and epigenetic alterations of LIT1 and H19. Am J Hum Genet 72:156-160

98. Maher ER, Brueton LA, Bowdin SC, Luharia A, Cooper W, Cole TR, Macdonald F, Sampson JR, Barratt CL, Reik W, Hawkins MM 2003 Beckwith-Wiedemann syndrome and assisted reproduction technology (ART). J Med Genet 40:62-64

99. Gicquel C, Gaston V, Mandelbaum J, Siffroi JP, Flahault A, Le Bouc Y 2003 In vitro fertilization may increase the risk of Beckwith-Wiedemann syndrome related to the abnormal imprinting of the KCN1OT gene. Am J Hum Genet 72:1338-1341

100. Cox GF, Burger J, Lip V, Mau UA, Sperling K, Wu BL, Horsthemke B 2002 Intracytoplasmic sperm injection may increase the risk of imprinting defects. Am J Hum Genet 71:162-164

101. Orstavik KH, Eiklid K, van der Hagen CB, Spetalen S, Kierulf K, Skjeldal O, Buiting K 2003 Another case of imprinting defect in a girl with Angelman syndrome who was conceived by intracytoplasmic semen injection. Am J Hum Genet 72:218 219

102. Moll AC, Imhof SM, Cruysberg JR, Schouten-van Meeteren AY, Boers M, van Leeuwen FE 2003 Incidence of retinoblastoma in children born after in-vitro fertilisation. Lancet 361:309-310

103. Chang AS, Moley KH, Wangler M, Feinberg AP, Debaun MR 2005 The Association between Beckwith-Wiedemann syndrome and assisted reproductive technology: a case series of 19 patients. Fertil Steril 83:349-354

104. Zech H, Vanderzwalmen P, Prapas Y Lejeune B, Duba E, Schoysman R 2000 Congenital malformations after intracytoplasmic injection of spermatids. Hum Reprod 15:969-971

105. Shamanski FL, Kimura Y, Lavoir M, Pedersen RA, Yanagimachi R 1999 Status of genomic imprinting in mouse spermatids. Hum Reprod 14:1050-1056

106. Kerjean A, Dupont J, Vasseur C, Le Tessier D, Cuisset L, Paldi A, Jouannet P, Jeanpierre M 2000 Establishment of the paternal methylation imprint of the human H19 and MEST/PEG1 genes during spermatogenesis. Hum Mol Genet 9:2183-2187

107. Ariel M, Cedar H, McCarrey J 1994 Developmental changes in methylation of spermatogenesis-specific genes include reprogramming in the epididymis. Nat Genet 7:59-63

108. Zech H, Vanderzwalmen P, Prapas Y, Lejeune B, Duba E, Schoysman R 2000 Congenital malformations after intracytoplasmic injection of spermatids. Hum Reprod 15:969-971

109. Bonduelle M, Liebaers I, Deketelaere V, Derde M, Camus M, Devroey P, Van Steirteghem A 2002 Neonatal data on a cohort of 2889 infants born after ICSI) 1991-1999 and of 2995 infants born after IVF (1983-1999). Hum Reprod 17:671694

110. Trounson A, Anderiesz C, Jones G 2001 Maturation of human oocytes in vitro and their developmental competence. Reproduction 121:51-75

111. Barnes FL, Kausche A, Tiglias J, Wood C, Wilton L, Trounson A 1996 Production of embryos from in vitro- matured primary human oocytes Fertil Steril 65:11511156

112. Amir RE, Zoghbi HY 2000 Rett Syndrome: methyl-CpG-binding protein 2 mutations and phenotype-genotype correlations. Am J Med Genet 97:147-152

113. Knoll JH, Nicholls RD, Magenis RE, Graham JM Jr, Lalande M, Latt SA 1989 Angelman and Prader-Willi syndromes share a common chromosome 15 deletion but differ in parental origin of the deletion. Am J Med Genet 32:285-290 